\section{Metrópole e região: dilemas da pactuação da saúde. O caso da Região Metropolitana da Baixada Santista, São Paulo, Brasil}

\author{
Metropolitan and regional health planning: \\ dilemmas of the Pact for Health in the Baixada \\ Santista Metropolitan Area, São Paulo State, Brazil
}

\author{
1 Faculdade de Saúde \\ Pública, Universidade de São \\ Paulo, São Paulo, Brasil. \\ 2 Instituto de Saúde, \\ São Paulo, Brasil. \\ 3 Instituto Butantan, \\ São Paulo, Brasil. \\ Correspondência \\ A. M. Z. Ianni \\ Faculdade de Saúde Pública, \\ Universidade de São Paulo. \\ Av. Dr. Arnaldo 715, \\ São Paulo, $S P$ \\ 01246-904, Brasil. \\ aureanni@usp.br
}

\section{Abstract}

This paper focuses on the relationship between metropolitan and regional health planning based on the processes of regionalization and the Pact for Health in the Baixada Santista Metropolitan Area, São Paulo State, Brazil. The method used was a case study in two stages, namely during initial implementation of the Pact for Health (2007) and the Regional Administration Committees (CGR) and in 2010. Municipal and regional health systems managers and the director of the Metropolitan Agency were interviewed, and records were analyzed from ten years of meetings of the Regional Inter-Administration Committee and the Regional Development Council. Four issues emerged: financing and infrastructure; health services utilization; inefficiency of the Regional Health Administration's instruments and decision-making levels; and the relationship between different levels in the Administration. Metropolitan health management remained as an underlying issue, appearing only incidentally or tangentially to regional management. Despite some limitations, the CGR has been legitimized as a space for regional health management.

Metropolis; Regional Health Planning; Health Policy
Aurea Maria Zöllner Ianni 1 Paulo Henrique Nico Monteiro 2 Olga Sofia Fabergé Alves 3 Maria de Lima Salum e Morais 2 Renato Barboza 2

\section{Introdução}

No mundo contemporâneo, cresce o desafio da gestão dos sistemas de saúde nas regiões metropolitanas, pois nelas se articulam processos demográficos, socioeconômicos e político-culturais de âmbito local, regional e até mesmo global 1,2 . Nesse contexto, a regionalização da saúde no Brasil, desencadeada com a promulgação do Pacto pela Saúde em $2006{ }^{3}$, coloca novos desafios para a gestão metropolitana. Regionalização e metropolização apresentam tensões de caráter teórico e prático, bem como de natureza interdisciplinar e interinstitucional. Trata-se de uma articulação que produz uma "dupla identidade" - metrópole e região - fazendo emergir impasses e desafios para a gestão loco-regional.

$\mathrm{O}$ artigo apresenta os resultados de pesquisa desenvolvida no âmbito do Projeto de Expansão e Consolidação do Saúde da Família (PROESF), no período compreendido entre 2007 e 2010, na Região Metropolitana da Baixada Santista, sob a coordenação do Instituto de Saúde da Secretaria de Estado da Saúde de São Paulo (SES-SP). Realizada nos municípios de Cubatão, São Vicente, Praia Grande, Santos e Peruíbe, consistiu na investigação sobre os condicionantes do acesso aos serviços de saúde na Atenção Básica ${ }^{4} \mathrm{em}$ sua relação com o processo de regionalização no período de transição da implantação do Pacto pela Saúde na região. 
Por ser uma região territorial que se constitui simultaneamente como espaço metropolitano e de regionalização da saúde, o estudo procurou investigar as tensões intrínsecas a esta "dupla identidade”, segundo a percepção dos gestores da Região Metropolitana da Baixada Santista.

\section{Metrópole, região e saúde: a dança dos conceitos}

O Pacto pela Saúde define região de saúde como "recortes territoriais inseridos em espaços geográficos contínuos (...) tendo como base a existência de identidades culturais, econômicas e sociais, assim como de redes nas áreas de comunicação, infraestrutura, transportes e saúde" 3 (p. 26). Essa definição pressupõe espaços interconectados, dinâmicos e com vida socioeconômica, política e cultural em processo. O Pacto define também a cartografia de uma região de saúde, que pode "assumir diferentes desenhos, desde que adequados às diversidades locais, mesmo que não acompanhando as divisões administrativas regionais já utilizadas por alguns estados na organização de seus trabalhos" 3 (p. 26). Não se define região, portanto, com base em estruturas administrativas preexistentes ou apenas nos equipamentos de saúde instalados, mas segundo as necessidades de saúde da população em articulação com as dinâmicas sociais gerais 5 , além da rede de serviços oferecidos e demais recursos da região.

Agregando conteúdo a essas definições, o Pacto ainda indica o caráter político do processo envolvido na constituição de uma região - a regionalização -, entendida como "a diretriz que orienta o processo de descentralização das ações e serviços de saúde e os processos de negociação e pactuação entre os gestores" 3 (p. 19).

A região metropolitana, compreendida como uma cidade articulada a diferentes subúrbios, pressupõe uma extensão territorial e um contingente populacional expressivos e diversidade de atividades socioeconômicas - lócus privilegiado de inovação, complexidade e sobreposição de redes como as de transporte, informação, comunicação, cultura, lazer, consumo, saúde, educação etc. Implica, ainda, processos contínuos de ocupação urbana com diferenciação intra e intermunicipais 6,7. Nessa perspectiva, o sentido da metropolização é o de processos relativos aos espaços de fluxos em dimensão territorial 8 . Por isso, a ideia de região, quando referida a conglomerados urbanos, é imanente à ideia de metrópole ${ }^{9}$.

Em cenários de intensa urbanização, os processos de metropolização e regionalização da saúde são fenômenos que se sobrepõem, apre- sentando contradições que decorrem das diferentes lógicas históricas de sua implementação.

A institucionalização das regiões metropolitanas no Brasil tem suas bases na década de 1970, durante o regime militar, o que vincula sua história institucional ao autoritarismo, fazendo com que seguisse sempre à margem de todas as reflexões sobre a política urbana brasileira e continuando, até os dias de hoje, à margem das políticas territoriais 9. Em decorrência dessas raízes, os aspectos formais e administrativos das regiões metropolitanas não levam em conta o uso real do território nem seus fluxos. Esse é o motivo pelo qual o território "usado", segundo Souza 9, não foi ainda incorporado à dinâmica política locoregional, sendo ignorado pelos governos federais e estaduais. Para a autora, poucos governos fazem política incorporando o território em sua totalidade - o geográfico e os seus usos.

A regionalização da saúde no Brasil, por sua vez, impulsionada pelo Pacto pela Saúde, acontece num desdobramento do Sistema Único de Saúde (SUS) implantado com a Constituição de 1988. Ocorre num contexto de consolidação política democrática e de reestruturação do aparelho de Estado, que começa com o fim do período militar. Ainda que na Saúde tenha havido ações de descentralização e regionalização em períodos anteriores ao SUS, como o caso do Sistema Unificado e Descentralizado de Saúde (SUDS) por exemplo, foi com as Normas Operacionais Básicas (NOBs) e a Norma Operacional da Assistência à Saúde (NOAS) que este processo alcançou maior institucionalidade, vindo a consolidar-se com a promulgação do Pacto 10,11,12,13.

A contradição, ou dissociação, entre esses dois projetos político-administrativos - o das regiões metropolitanas e o da regionalização da saúde - merece ser devidamente considerada, pois os protagonistas desses processos situamse diferentemente referenciados no cenário político e de gestão loco-regional, o que resulta em objetivos e estratégias muitas vezes dissonantes, moldados por trajetórias e interesses institucionais diversos.

Ainda que construídos historicamente de maneira autônoma e independente, ambos os processos se assemelham quanto à concepção de território - o que vai explicar, de certa forma, a relativa ausência da vida social, pública e política nos dois processos. Mesmo que as formulações atuais contenham, em ambos os casos, o conceito de território "usado" e em fluxos, é, na realidade, o território cartográfico, dos limites municipais e administrativos que vige nas práticas institucionais.

Diferentes autores 14,15, ao discutirem a falta de estatuto político das Regiões Metropolita- 
nas, dizem que vários estados brasileiros não avançaram na incorporação da gestão do território como variável importante - fato que acabou transformando-se num limitante da gestão metropolitana.

Processo semelhante ocorreu na área da saúde. Marques \& Najar 16, discutindo as intervenções sanitárias urbanas do século XIX e no decorrer do século XX, afirmam que as corporações da saúde pública se concentraram mais nos aspectos nosológicos, de administração e de planejamento dos serviços de saúde, promovendo o expurgo da temática espacial das preocupações centrais da saúde pública - uma questão que foi tratada mais como elemento de contextualização do que constitutiva 17,18. Essa herança pode ser o motivo pelo qual a regionalização na saúde, em muitos casos, fique restrita à simples normalização, sem que seu processo se converta em político.

É importante mencionar, ainda, que, no âmbito da gestão pública no Brasil, o processo de descentralização ocorrido pós-Constituição de 1988 trouxe algumas dificuldades como: pouca ênfase na questão metropolitana, manutenção do patrimonialismo local, poucos incentivos à cooperação intergovernamental e uma atuação mais autarquizada dos níveis de governo do que o estabelecimento de laços entre eles, afetando, profundamente, a efetividade das políticas públicas 19 .

No âmbito do SUS, a descentralização provocou desigualdades e competências concorrentes entre os entes federados, exigindo novos paradigmas administrativos para operá-los 20,21. A perspectiva da superação da dicotomia administração e política 22 tornou imperiosa uma gestão intergovernamental baseada em processos de pactuação com responsabilidade solidária, cooperação e negociação, tendo por base a redução das disputas predatórias e o estímulo ao compartilhamento de responsabilidades 20,21.

Um dos desafios, portanto, é o de articular o processo de descentralização e regionalização em curso no SUS aos diferentes cenários políticos loco-regionais na perspectiva do rompimento do patrimonialismo local e da atuação autarquizada entre os níveis de governo. Se, por um lado, a dinâmica metropolitana demanda uma revalorização da cooperação em detrimento do individualismo localista 4,23 , também na pactuação regional é mister implementar esta proposição. Nesse sentido, a falta de estatuto da ideia de território nas políticas da gestão metropolitana e da regionalização na saúde repercute nos processos políticos regionais, produzindo conflitos e desafios que interferem na condução e consolidação da pactuação regional que, por sua vez, também apresenta conflitos decorren- tes do processo de descentralização da gestão pública no país.

Em casos como o da Região Metropolitana da Baixada Santista, nos quais os fenômenos da metropolização, regionalização e pactuação da saúde se sobrepõem, esses problemas ficam claramente explicitados, podendo, no entanto, se bem compreendidos, estimular a busca de soluções criativas e inovadoras para a gestão da saúde.

\section{Regionalização da saúde no Estado de São Paulo no contexto do Pacto pela Saúde: a Região Metropolitana da Baixada Santista}

O Estado de São Paulo constitui um laboratório especial para estudos que enfoquem a relação metrópole e saúde, pois possui o maior número de regiões metropolitanas do país: Região Metropolitana de São Paulo, Região Metropolitana de Campinas e Região Metropolitana da Baixada Santista, onde vivem cerca de 24 milhões de habitantes (58,5\% da população do Estado de São Paulo e $12,9 \%$ do total do país), com um Produto Interno Bruto (PIB) correspondente a $63,2 \%$ do PIB estadual e quase $20 \%$ do nacional 24.

A Baixada Santista, formalizada como Região Metropolitana em 1996, é composta por nove municípios: Peruíbe, Itanhaém, Mongaguá, Praia Grande, São Vicente, Cubatão, Santos, Guarujá e Bertioga. Abrange cerca de $1 \%$ da área do estado e tem uma população fixa de cerca de 1,7 milhão de habitantes, segundo estimativas de 201024 . Dada sua vocação turística, a população praticamente dobra em períodos de veraneio 25 . Essa característica, embora não conste das estatísticas demográficas oficiais, causa impactos decisivos sobre o processo de produção do espaço urbano, gerando demandas por habitações, investimentos em infraestrutura e serviços 26.

A Baixada Santista, além de região metropolitana administrativa, constitui-se, também, como região de saúde. Essa "dupla identidade" coloca aos gestores vários desafios: aos problemas e impasses da regionalização da saúde, retomados com o Pacto pela Saúde de 2006, sobrepõem-se os problemas herdados do processo de implantação da região metropolitana, ocorrido na década de 1990. Essa ambivalência acumula contradições que permeiam os processos da gestão política e administrativa da pactuação regional.

A implantação do Pacto pela Saúde foi desencadeada no Estado de São Paulo em 2007. No primeiro semestre daquele ano, as coordenadorias da SES-SP e os Departamentos Regionais de Saúde (DRS), junto aos novos Colegiados de Gestão Regional (CGR) ajustaram as diretrizes, objetivos, 
ações estratégicas, metas e indicadores de acompanhamento da execução do Plano Regional de Saúde, além de revisar o Plano Diretor de Regionalização (PDR). Corroborando o argumento de Azevedo \& Mares Guia 15 de que, para alcançar níveis adequados de governança torna-se vital que a política ganhe legitimidade perante os atores políticos relevantes, a SES-SP incorporou ao processo de implantação do Pacto o apoio institucional de oito centros universitários do estado, a fim de fortalecer a capacidade de gestão dos CGR 27. Esse processo foi subvencionado por dois anos tendo se estendido pelo período compreendido entre 2007 e 2010, em função da diversidade das regiões do estado. Neste estudo, será esse período o considerado como de institucionalização do Pacto pela Saúde no estado. O Conselho dos Secretários Municipais de Saúde de São Paulo (COSEMS-SP), por sua vez, definiu apoiadores regionais para acompanhar a elaboração dos planos e fortalecer os gestores municipais nos CGR, reafirmando uma política de governança democrática.

\section{Método}

A pesquisa caracterizou-se como estudo de caso 28 e correspondeu ao período de transição da regionalização na Baixada Santista, de 2007 a 2010, anterior e posterior à implantação do Pacto pela Saúde.

Foram realizadas entrevistas semiestruturadas com os gestores municipais e regional e com a direção técnica da Agência Metropolitana da Baixada Santista (AGEM) no ano de 2007. Em 2010, entrevistou-se o apoiador do COSEMS-SP na perspectiva de captar a percepção de quem acompanhou o processo de transição.

Com base na análise de conteúdo 29,30, selecionaram-se as referências dos gestores aos processos de regionalização da saúde, metropolização e pactuação. Focaram-se: as perspectivas para a gestão regional no cenário da implantação do Pacto pela Saúde; a trajetória da pactuação quanto às suas dificuldades e facilidades; o papel dos municípios e do estado nesse processo; as noções e relações região-metrópole; as dinâmicas metropolitanas intervenientes na atenção à saúde; e a interface Comissão Intergestora Regional (CIR) - AGEM.

Também foram analisadas as atas da CIR instância correlata do atual CGR - entre os anos de 1997 e 2007, e as atas do Conselho de Desenvolvimento da Baixada Santista (CONDESB) vinculado à AGEM, entre os anos de 1996 e 2006. Essas atas foram consideradas documentos: registros históricos que expressam uma inten- cionalidade de discurso, carregados de aspectos informativos e expressão de um pensamento coletivo ${ }^{31}$, no caso, o dos gestores da região.

O projeto foi aprovado pelo Comitê de Ética em Pesquisa do Instituto de Saúde, em atenção à Resolução $n^{o}$. 196/96 do Conselho Nacional de Saúde.

\section{Resultados e discussão}

A apresentação dos resultados e a discussão foram organizadas em torno de dois temas centrais: o da descentralização/regionalização e o da metropolização.

Quanto ao tema da descentralização/regionalização, identificaram-se os seguintes aspectos: utilização de serviços de saúde por usuários residentes em outros municípios, denominada aqui como "invasão e evasão"; relação entre os níveis de gestão do SUS; ineficiência das instâncias e instrumentos de gestão regional da saúde; e financiamento e infraestrutura.

No que se refere à "invasão/evasão" dos usuários, os gestores pareceram compreender e justificar esse fluxo de deslocamento quando se trata do acesso aos serviços de média e alta complexidades, especialmente em direção ao município polo, Santos, que possui uma rede com mais recursos. Entretanto, queixaram-se do fato de que isso também ocorria na Atenção Básica, penalizando os municípios que oferecem uma rede estruturada e premiando, de alguma forma, aqueles cuja rede era de pior qualidade ou menos organizada.

Pode-se deduzir que essa tensão seria atenuada se os gestores compreendessem que os limites físicos entre municípios são pouco significativos para entender a dinâmica demográfica regional, considerando-se que ela ocorre num espaço territorial contínuo 26 . Pesquisas recentes, que vêm discutindo a dinâmica metropolitana e o acesso aos serviços de saúde 32 , apontam que, dentre os principais obstáculos à estruturação do sistema, predominam aqueles decorrentes do perfil da urbanização e das desigualdades inter e intramunicipais. Bosquat \& Nascimento 33 , relatando pesquisa sobre a Região Metropolitana de São Paulo, concluíram que os moradores se deslocam de seus locais de origem por não encontrarem respostas à sua demanda na esfera local da atenção e sim no sistema regionalizado, e revelam que são as sub-regiões metropolitanas aquelas capazes de reter a grande maioria dos fluxos dos usuários originados em sua própria área, ou seja, no que se refere ao território "usado”, as lógicas de deslocamentos são regionais e não municipais. 
As formas de ocupação do espaço intraurbano merecem o interesse dos gestores no contexto da regionalização, pois, na Região Metropolitana da Baixada Santista, ocorrem os seguintes fenômenos: a migração intrametropolitana, a evasão demográfica (ou emigração intrametropolitana) da região central - especialmente do municípiopolo para as demais da região - e a imigração para os municípios periféricos. A evasão demográfica tem apresentado um perfil diferenciado; a classe média muda-se para o Guarujá e áreas nobres de Bertioga, e a população mais pobre para os municípios ao sul, Praia Grande, Mongaguá e Peruíbe, que enfrentam um adensamento urbano de ocupações irregulares 26 .

"A gente percebe o crescimento assim... totalmente desordenado das cidades, (...) prejudica demais" (Entrevistado A).

Sobre as altas taxas de crescimento demográfico dos municípios em anos recentes, o mesmo gestor diz: "A gente notou isso no cadastro, no Cartão Saúde”. Esse fenômeno impacta enormemente os serviços, conformando um subsistema construído pelos usuários em paralelo ao sistema formalmente instalado.

A descentralização da saúde nos anos de 1990, marcada pela transferência vertical das responsabilidades e recursos do Ministério da Saúde para os municípios, levou à fragmentação decisória e a disputas predatórias ${ }^{4}$. Em 2002, com a retomada da regionalização pela NOAS 01, objetivou-se a integração dos sistemas municipais de saúde, um processo que enfrentou obstáculos decorrentes do cenário anterior; sob o imperativo do acesso universal, houve uma intolerância da manutenção de barreiras de acesso entre municípios acentuando a lógica da "exportação" e "importação" intermunicipal de serviços, e que se articulou ao fenômeno da mobilidade dos cidadãos em busca de oportunidades de acesso a serviços localizados em outros municípios 4 . Ou seja, o comportamento político dos atores no processo da descentralização, muito paradoxalmente, incorporou e simultaneamente desconsiderou o território como elemento de gestão, com a finalidade de acomodar a pressão da demanda pelos serviços de saúde.

O Município de Peruíbe, por sua localização geográfica, ocupa um lugar peculiar no cenário regional. Tem como referência tanto o município polo quanto o Município de Pariquera-Açu, no Vale do Ribeira - outra região de saúde na qual se situa um hospital regional para onde a população de Peruíbe se desloca -, pois, segundo o gestor, neste último, a demanda é menor.

Esse caso é exemplar da tensão regionalização/metropolização. A localização do município no território metropolitano dificulta o acesso ao município polo e, no âmbito da pactuação regional, o município não encontra eco para suas demandas e necessidades, sendo, inclusive, prejudicado pela fragilidade das decisões acordadas. Por isso, manifestam entusiasmo com a proposta de reestruturação das Regionais de Saúde, a da Baixada em especial, pois acreditam num novo desenho para a região com a criação de microrregiões, incorporando municípios da região vizinha. Nessa linha de atuação, estabeleceram um convênio para partos de alto risco com municípios contíguos às atuais fronteiras regionais. Há uma percepção de que essa microrregião tem potencial de crescimento em função do desenvolvimento do turismo local, da implantação das plataformas marítimas de gás e do uso do aeroporto de Itanhaém, e se propõem a pautar esta discussão no CGR que está sendo criado.

"Nós somos os que mais acreditaram em regionalização aqui na Baixada. Chegamos a liberar um milhão e meio de reais para a construção do hospital em Itanhaém, acreditando que o hospital fosse regionalizado e acabou não sendo; nós precisamos de parceiro fora daqui" (Entrevistado A).

No que se refere à relação entre os níveis de gestão do SUS e à ineficiência das instâncias e instrumentos de gestão regional da saúde, predomina a dinâmica autárquica no processo de descentralização/regionalização em curso e que foi objeto de crítica unânime dos gestores. Para os gestores dos municípios, o DRS possuía fragilidades tanto técnicas quanto políticas para exercer sua função precípua de articulação regional e apoio técnico aos municípios. Apontaram, ainda, que o DRS, em função de uma cultura centralizadora, exercia controle no espaço da CIR, fazendo prevalecer o caráter vertical da relação estado/municípios. De forma diametralmente oposta, o gestor regional enfatizou o nãocumprimento dos acordos por parte dos municípios e a falta de compromisso com as questões de caráter regional.

Essa dinâmica se reflete na ineficiência das instâncias formais de pactuação. Os gestores referiram que a CIR caracterizava-se como um espaço meramente homologatório; a Programação Pactuada Integrada (PPI) e o Plano Diretor Regional (PDR) não se efetivaram como instrumentos de regulação e as demandas municipais relacionadas à alta complexidade eram resolvidas informalmente com base em relações interpessoais. Para eles, no âmbito da ação intersetorial, nem o CONDESB nem a AGEM consistiam em espaços legítimos de representação e pactuação regional. Trata-se do que Bahia et al. 34 referem como a falta de operacionalidade e preponderância nas agendas dos secretários de saúde de políticas horizontalizadas e intersetoriais. 
Verificou-se que a falta de aporte financeiro e de infraestrutura por parte do nível estadual sobrecarregava o município responsável pela atenção direta, desencadeando uma "competição intermunicipal” pelos investimentos e comprometendo o processo de pactuação regional. A análise das atas da CIR confirmou esse fato, pois, em $90 \%$ delas, há reivindicações de suplementação dos recursos e aumento do teto financeiro municipal para a média e alta complexidades. Nas atas do CONDESB o tema da saúde aparece muito pouco e, quando isto ocorre, predomina a falta de infraestrutura do setor.

O membro do COSEMS-SP, que traz o olhar de quem acompanhou o processo, identificou avanços e dificuldades da regionalização. Em sua percepção, os municípios parecem reconhecer a importância política do CGR no processo de pactuação e buscam eliminar os pontos de atrito nas discussões bilaterais das Câmaras Técnicas, as quais muitas vezes acabam por substituir o CGR pois apresentam maior densidade, tornando-se o palco real dos conflitos e das soluções alternativas. Observa que alguns municípios continuam pleiteando soluções para seus problemas à revelia da discussão regional, muitas vezes em conflito com a construção de um sistema, e acredita que o espaço do CGR ainda não foi incorporado como instância colegiada tanto pelo gestor estadual quanto pela maioria dos gestores municipais.

No que se refere à descentralização/regionalização, conclui-se que fatores como a dinâmica política loco-regional, a dinâmica territorial e demográfica, a fragilidade dos instrumentos de pactuação, a autarquização dos níveis de gestão e a competição por recursos dificultam a efetivação da pactuação numa perspectiva solidária e cooperativa.

Com relação à ideia de metrópole, bem como à da gestão do sistema de saúde em cenário metropolitano, os resultados das entrevistas de 2007 indicaram uma grande invisibilidade do tema para o gestor local e regional. Apenas um deles afirmou que: "A visão metropolitana, na realidade, hoje ela é feita sob pressão, não é feita por pactuação. Então acho que falta os gestores sentarem, o estado sentar como igual e a gente pactuar. Acho que falta avançar a visão regional; ai depende de PPI, PDR e pactuação" (Entrevistado C). Ou seja, para esse gestor, a metropolização passa pela pactuação.

A maioria dos entrevistados revelou uma incompreensão conceitual de região metropolitana. Um deles disse que "Aqui não é uma região metropolitana por definição. Aqui é um aglomerado urbano (...) a maioria dos problemas não são problemas identificados em comum pelos nove municípios" (Entrevistado D). Mais enfática foi essa outra fala: "Pra nós, a metropolização não trouxe nenhum tipo de coisa diferente (...). Nós aqui não nos sentimos parte de uma região metropolitana..." (Entrevistado A). Para além do desconhecimento sobre o significado da metropolização, os gestores indicam, por esses depoimentos, que esse fenômeno não faz diferença para eles.

Conclui-se que o sentimento de não-pertencimento resultante da exclusão concreta que a dinâmica metropolitana produz acaba por se refletir nas práticas e estratégias da gestão em saúde.

Um dos municípios, que se vê isolado da região por causa de uma rodovia, questiona sua inserção na área metropolitana, evidenciando o quanto o fluxo do território "usado" interfere e determina sua percepção e a inserção real na área. Com exceção desse município, todos os demais se reconhecem, de uma forma ou de outra, pertencendo à Região Metropolitana da Baixada Santista, pelo menos no âmbito administrativo: "A visão metropolitana da saúde tem que existir, não adianta. Agora, pra que isso aconteça, precisa haver a pactuação" (Entrevistado H). Essa afirmação reitera a determinação da dinâmica metropolitana nas questões de saúde, cuja solução passa, necessariamente, pela articulação política regional - a pactuação.

A despeito das dificuldades da regionalização do SUS na Região Metropolitana da Baixada Santista, é importante destacar que o setor saúde foi o que mais avançou neste processo comparativamente aos demais, como a habitação, o planejamento urbano, os transportes, o meio ambiente. Aspectos como o financiamento, a infraestrutura, a migração pendular da população para a utilização dos serviços e a ineficiência das instâncias formais de pactuação acirram a competição entre os entes envolvidos, mas também aguçam a percepção sobre a necessidade da integração regional. Nesse sentido, a dimensão territorial do sistema de saúde pode desempenhar um papel fundamental no estímulo das políticas sociais intersetoriais, o que se constitui, ainda, num grande desafio 20,35.

Adicionalmente, a fragilidade política dos colegiados de gestão - tanto da antiga CIR quanto do atual CGR - é fator dificultante da consecução de qualquer projeto de caráter intermunicipal ou metropolitano. Na medida em que esse processo pressupõe o deslocamento de uma lógica local de gestão para uma lógica que contemple os aspectos regionais metropolitanos, a pactuação regional precisa reconhecer a dinâmica urbana como determinante da produção da saúde. Fica evidente a necessidade de uma regionalização que identifique padrões e tendências espaciais 
de disputa política entre os diferentes atores envolvidos e de solidariedade entre os parceiros 21 , com vistas à consolidação de uma pactuação regional solidária.

\section{Considerações finais}

As formas pelas quais as cidades e as regiões metropolitanas são ocupadas refletem uma determinada estrutura social, condicionando-a. É fundamental conhecer e esquadrinhar os recursos metropolitanos, pois eles expressam poderes e segregações sociais estruturais. Um projeto de desenvolvimento em escala metropolitana só será impulsionado e sustentado por questões abrangentes que encontrem respostas efetivas nessa escala territorial e de gestão.

O processo de regionalização desencadeado pelo setor saúde configura-se como um espaço político-territorial que expressa o ideário do SUS de garantia da universalidade e da integralidade do acesso aos serviços de saúde. Esse processo requer uma gestão baseada na cooperação e compartilhamento entre os entes envolvidos, que só pode ser alcançada por meio de uma pactuação que enfrente os desafios da autarquização dos níveis de gestão e da necessária qualificação das instâncias e instrumentos de gestão regional. Trata-se do que propõe Abrucio 19 (p. 95): “Uma agenda de longo prazo para reformar a gestão pública brasileira depende, como em qualquer outro campo de políticas públicas, não só de ideias e análises. Acima de tudo, é preciso constituir coalizões".

A análise da experiência da regionalização na Baixada Santista revelou uma contradição: a fragilidade do estatuto da metrópole e o avanço da implementação do SUS na região por meio da regionalização no âmbito do Pacto de 2006. Essa contradição se revela em algumas questões que puderam ser observadas na pesquisa. Tanto os atores atinentes à gestão metropolitana, sensu strictu, como a AGEM, por exemplo, quanto os atores do sistema de saúde atuam baseados em uma concepção restrita de território, na acepção mais propriamente cartográfica, sem incorporar as concepções de território "usado", vivo, em fluxos. Nesse sentido, reafirma-se o que Gadelha et al. 35 (p. 3009) dizem sobre a concepção de regionalização na saúde, que "tem se restringido às questões relativas à organização da rede de serviços no âmbito intraestadual, sem a incorporação de uma lógica territorial mais abrangente e a articulação com outras esferas da política pública”.

Politicamente, no entanto, é o setor saúde que protagoniza o processo democrático de des- centralização das políticas públicas na região, por meio do processo de descentralização/regionalização que vem sendo implementado. Está, nesse sentido, e de alguma forma, "criando" território vivo, o que quer dizer que, conscientemente ou não, os gestores da saúde, ao implementarem sua agenda setorial, desencadeiam um novo fenômeno loco-regional, no caso específico deste estudo: o território.

Esse paradoxo, o da "criação" de território vivo, "usado", político, em fluxos e a invisibilidade dessas dimensões do território aos olhos dos gestores, talvez advenha do fato de que o processo de regionalização na Baixada Santista tenha ocorrido sem nenhuma alteração dos municípios envolvidos, já que o desenho metropolitano administrativo anterior ao Pacto foi mantido, não tendo sido incorporado ou retirado nenhum município. É provável que isso tenha contribuído para a imperceptibilidade da importância da metropolização no processo de regionalização e pactuação em curso.

Ainda que a dimensão metropolitana da territorialidade da região de saúde na Baixada Santista possa passar por invisível para a maioria dos gestores, ela não deixa de estar presente e de estar também em processo de constituição, transformação.

Por fim, é a pactuação política que catalisa esses dois processos e, portanto, suas contradições. É a pactuação na Região Metropolitana da Baixada Santista que vem fazendo aflorar os desafios internos ao setor saúde e externos a ele. A implantação dos CGR "permitiu um intenso envolvimento dos secretários e técnicos. (...) A Secretaria Estadual de Saúde tornou-se mais permeável às demandas dos municípios, o que tem permitido um profícuo diálogo e a perspectiva de se abrir agendas até então interditadas" 36 (p. 20). Entretanto, os resultados deste estudo mostram o quanto as estratégias anteriormente utilizadas pelos gestores ainda persistem.

Ao criar território político vivo na Baixada Santista, o setor saúde desafia os demais setores da região a enfrentar e interligar as políticas sociais 20 . $\mathrm{O}$ fato de que os gestores locais e regional de saúde não identifiquem o CONDESB como instância articuladora das políticas intersetoriais expressa, particularmente, uma necessidade do setor saúde em função de seu protagonismo na região.

É importante mencionar que, na implementação do Pacto pela Saúde no Estado de São Paulo, era unânime entre os gestores da Região Metropolitana da Baixada Santista a expectativa positiva em relação a esse processo, especialmente quanto ao papel do CGR, revelando o grande potencial de aderência ao Pacto. 
Os resultados revelaram as tensões existentes entre os processos de metropolização e regionalização da saúde no âmbito do sistema loco-regional, e que se expressam na pactuação política na região. A superação dessa contradição contribuirá para o desenvolvimento regional na perspectiva do que Ribeiro 37 (p. 11) indica, quando diz que "as metrópoles competitivas são as que recusaram desmontar os seus sistemas de proteção social".

\section{Resumo}

O trabalho aborda aspectos da relação entre metropolização e regionalização em saúde, tendo por base os processos de regionalização e pactuação na Região Metropolitana da Baixada Santista, São Paulo, Brasil. Trata-se de estudo de caso, realizado em dois momentos: o primeiro, no início da implementação do Pacto pela Saúde (2007) e dos Colegiados de Gestão Regional (CGR), e o segundo, em 2010. Foram entrevistados gestores municipais e regionais do SUS e a direção da Agência Metropolitana. Também foram analisadas atas de dez anos de reuniões da Comissão Intergestora Regional e do Conselho de Desenvolvimento da Baixada Santista. Emergiram quatro grandes temas: financiamento e infraestrutura; utilização de serviços; ineficiência das instâncias e instrumentos de gestão; relação entre os níveis de gestão. Permaneceu latente a questão da metropolização, que aparece de forma incipiente ou tangencial à gestão regional. Avalia-se que apesar de algumas limitações, o CGR vem se legitimando como espaço de gestão regional.

Metrópoles; Regionalização; Política de Saúde
Na ausência de um plano orientador de reformas da gestão pública brasileira ${ }^{19}$, a regionalização da saúde em curso no Estado de São Paulo, pela complexa configuração do seu sistema e pelo protagonismo na implantação da regionalização, traz, neste sentido, contribuições importantes para experiências semelhantes na organização de sistemas de saúde.

\section{Colaboradores}

A. M. Z. Ianni, P. H. N. Monteiro e O. S. F. Alves elaboraram o artigo. M. L. S. Morais e R. Barboza realizaram a leitura crítica e prepararam o manuscrito. 


\section{Referências}

1. Santos M. Metamorfoses do espaço habitado. 4a Ed. São Paulo: Editora Hucitec; 1996.

2. Cooksey JA, Krieg RM. Metropolitan health policy development: barriers to implementation. J Public Health Policy 1996; 17:261-74.

3. Ministério da Saúde. Portaria GM nº. 399, de 22 de fevereiro de 2006. Divulga o Pacto pela Saúde 2006, Consolidação do SUS e aprova as Diretrizes Operacionais do Referido Pacto. http://dtr2001.saude. gov.br/sas/PORTARIAS/Port2006/GM/GM-399. htm (acessado em 28/Out/2010).

4. Barboza R, Ianni AMZ, Morais MLS, Alves OSF, Monteiro PHN, Ferrari F, et al. Acesso e estruturação da Atenção Básica na Região Metropolitana da Baixada Santista: uma análise dos gestores. In: Escuder MML, Monteiro PHN, Pupo LR, organizadores. Acesso aos serviços de saúde em municípios da Baixada Santista. São Paulo: Instituto de Saúde; 2008. p. 29-50.

5. Machado JA. Pacto de gestão na saúde: até onde esperar uma regionalização solidária e cooperativa? Rev Bras Ciênc Soc 2009; 24:105-93.

6. Gottdiener M. A produção do espaço urbano. São Paulo: Edusp; 1993.

7. Lencioni S. Reconhecendo metrópoles: território e sociedade. In: Silva CA, Freire DG, Oliveira FJG, organizadores. Metrópole: governo, sociedade e território. Rio de Janeiro: DP\&A Editora/Fundação de Amparo à Pesquisa do Estado do Rio de Janeiro; 2006. p. 41-57.

8. Meyer RMP. Atributos da metrópole moderna. São Paulo Perspect 2000; 14:3-9.

9. Souza MAA. Recompondo a história da região metropolitana: processo, teoria e ação. In: Silva CA, Freire DG, Oliveira FJG, organizadores. Metrópole: governo, sociedade e território. Rio de Janeiro: DP\&A Editora/Fundação de Amparo à Pesquisa do Estado do Rio de Janeiro; 2006. p. 27-40.

10. Vilaça-Mendes E. Uma agenda para a saúde. São Paulo: Editora Hucitec; 1999.

11. Guimarães RB. Rumos da regionalização da saúde Brasileira. In: Barcellos C, organizador. A geografia no contexto dos problemas de saúde. Rio de Janeiro: ABRASCO; 2008. p. 231-41.

12. Guimarães RB. Regiões de saúde e escalas geográficas. Cad Saúde Pública 2005; 21:1017-25.

13. Souza RR. A regionalização no contexto atual das políticas de saúde. Ciênc Saúde Coletiva 2001; 6:451-5.

14. Souza C. Regiões metropolitanas: trajetória e influência das escolhas institucionais In: Ribeiro LCQ organizador. Metrópoles: entre a coesão e a fragmentação, a cooperação e o conflito. São Paulo: Fundação Perseu Abramo/Rio de Janeiro: FASE/ Observatório das Metrópoles; 2004. p. 61-96.

15. Azevedo S, Mares Guia VR. Os dilemas institucionais da gestão metropolitana no Brasil. In: Ribeiro LCQ, organizador. Metrópoles: entre a coesão e a fragmentação, a cooperação e o conflito. São Paulo: Fundação Perseu Abramo/Rio de Janeiro: FASE/Observatório das Metrópoles; 2004. p. $67-110$.
16. Najar AL, Marques EC. A Sociologia urbana, os modelos de análise da metrópole e a saúde coletiva: uma contribuição para o caso brasileiro. Ciênc Saúde Coletiva 2003; 8:703-12.

17. Monken M, Barcellos C. Vigilância em saúde e território utilizado: possibilidades teóricas e metodológicas. Cad Saúde Pública 2005; 21:898-906.

18. Pessoto UC, Heimann LS, Boaretto RC, Castro IEN, Kayano J, Ibanhes LC, et al. Desigualdades no acesso e utilização dos serviços de saúde na Região Metropolitana de São Paulo. Ciênc Saúde Coletiva 2007; 12:351-62.

19. Abrucio FL. Trajetória recente da gestão pública brasileira: um balanço crítico e a renovação da agenda de reformas. Rev Admin Pública 2007; 41 (n. spe.):67-86.

20. Santos L, Andrade LOM. Redes interfederativas de saúde: um desafio para o SUS em seus vinte anos. Ciênc Saúde Coletiva 2011; 16:1671-80.

21. Guerreiro JV, Branco MAF. Dos pactos políticos à política dos pactos de saúde. Ciênc Saúde Coletiva 2011; 16:1689-98.

22. Fleury S. El desafío de la gestión de las redes de políticas. Revista Instituciones y Desarrollo 2002; 17. http://www.ebape.fgv.br/acadêmico/asp/ dsp_professor.asp?cd_pro36 (acessado em 09/ $\mathrm{Jul} / 2011$ ).

23. Machado CV, Lima LD. Os desafios da atenção à saúde em regiões metropolitanas. In: Giovanella L, Escorel S, Lobato LVC, Noronha, JC, Carvalho AI, organizadores. Políticas e sistema de saúde no Brasil. Rio de Janeiro: Editora Fiocruz/Centro Brasileiro de Estudos de Saúde; 2008. p. 945-77.

24. Empresa Paulista de Planejamento Metropolitano. Regiões Metropolitanas do Estado de São Paulo. 2010. http://www.emplasa.sp.gov.br/portalempla $\mathrm{sa} /$ infometropolitana/rmsp/rmesp.asp (acessado em 23/Set/2010).

25. Zündt C. Baixada Santista: uso, expansão e ocupação do solo, estruturação de rede urbana regional e metropolização. In: Cunha JMP, organizador. Novas metrópoles paulistas: população, vulnerabilidade e segregação. Campinas: Núcleo de Estudos de População, Universidade Estadual de Campinas; 2006. p. 305-36.

26. Cunha JMP, Jakob AAE, Young AF. Dinâmica demográfica intrametropolitana na Região Metropolitana da Baixada Santista, no período pós-1970. In: Cunha JMP, organizador. Novas metrópoles paulistas: população, vulnerabilidade e segregação. Campinas: Núcleo de Estudos de População, Universidade Estadual de Campinas; 2006. p. 399-434.

27. Seixas P. Avanços e perspectivas na política de gestão de recursos humanos: desenvolvimento de pessoas e qualificação dos profissionais do SUS/ SP. BIS Bol Inst Saúde 2009; 48:15-25.

28. Yin RK. Estudo de caso: planejamento e métodos. 3a Ed. Porto Alegre: Bookman Editora; 2005.

29. Quivy R, Campenhoudt LV. Manual de investigação em ciências sociais. Lisboa: Gradiva; 1998. 
30. Minayo MCS. Hermenêutica-dialética como caminho do pensamento social. In: Minayo MCS, Deslandes SF, organizadores. Caminhos do pensamento: epistemologia e método. Rio de Janeiro: Editora Fiocruz; 2002. p. 83-107.

31. Vieira MPA, Peixoto MRC, Khoury YMA. A pesquisa em História. São Paulo: Editora Ática; 1998.

32. Viana ALA, Lima LD, Ferreira MP. Condicionantes estruturais da regionalização na saúde: tipologia dos Colegiados de Gestão Regional. Ciênc Saúde Coletiva 2010; 15:2317-26.

33. Bosquat A, Nascimento VB. A metrópole paulista e a saúde. São Paulo Perspec 2001; 15:112-20.

34. Bahia L, Costa NR, Stralen CV. A saúde na agenda pública: convergências e lacunas nas pautas de debate e programas de trabalho das instituições governamentais e movimentos sociais. Ciênc Saúde Coletiva 2007; 12 Suppl:1791-818.
35. Gadelha CAG, Machado CV, Lima LD, Baptista TWF. Saúde e territorialização na perspectiva do desenvolvimento. Ciênc Saúde Coletiva 2011; 16:3003-16.

36. Assis E, Cruz VS, Trentin EF, Lucio HM, Meira A, Monteiro JCK, et al. Regionalização e novos rumos para o SUS: a experiência de um colegiado regional. Saúde Soc 2009; 18 Suppl 1:17-21.

37. Ribeiro LCQ. Apresentação. As metrópoles e a sociedade brasileira: futuro comprometido? In: Ribeiro LCQ, organizador. Metrópoles: entre a coesão e a fragmentação, a cooperação e o conflito. São Paulo: Fundação Perseu Abramo/Rio de Janeiro: FASE/Observatório das Metrópoles; 2004. p. 9-14.

Recebido em 16/Nov/2010

Versão final reapresentada em 06/Dez/2011

Aprovado em 31/Jan/2012 